\title{
Predictors and Significance of Orbital Fracture in Traumatic Brain Injury
}

\author{
Karuna Tamrakar Karki ${ }^{1}$, Pankaj Raj Nepal ${ }^{1}$ \\ ${ }^{1}$ Department of Neurosurgery, B and C Medical College Teaching Hospital and Research Center, Birtamod, \\ Jhapa. \\ Correspondence: \\ Dr Karuna Tamrakar Karki \\ Department of Neurosurgery, B \& C Medical College and Teaching Hospital \& Research \\ Center,Birtamode,Jhapa,Nepal. \\ Email: tamrakarkaruna@gmail.com
}

\begin{abstract}
Background and purpose: Orbital manifestation in traumatic brain injury though uncommon, is one of the major complications of traumatic brain injury that has to be addressed judiciously to prevent permanent visual loss. Material and Methods: 211 patients who underwent CT for traumatic brain injury in between September to December 2019 were prospectively examined for the orbital manifestation. Patients who had undergone CT head including orbit with 3D face RECON were only included in our study to remove the bias between fracture line and suture in plain CT scan. CT imaging was evaluated to identify and subtype the orbital fracture. Results: Total number of patients was 28, with mean age of 33.82 (SD 17.15) years. Majority of the patients were male which accounted $79 \%$ of sample size. There was $78 \%$ mild head injury followed by $18 \%$ and $4 \%$ moderate and severe head injury respectively. The most common type involved among all were blow out fracture and lateral orbital wall fracture. Clinically vision was abnormally around $21 \%$ of the cases, abnormal papillary reaction was seen in $25 \%$ of the cases around $93 \%$ of the cases had raccoon eye at the time of presentation. There was proptosis in around $14 \%$ of the patients and subconjunctival hemorrhage was seen in around $93 \%$ of the cases. Around $79 \%$ of the patients had intact vision at the time of presentation and $3.6 \%$ of the patients improved their vision during the course of treatment. Complete globe disruption who required evisceration of the eyeball was $10.7 \%$ and those who had abnormal vision at the time of presentation, $7.1 \%$ that did not improve their vision. Conclusions: orbital manifestations with either type of orbital fracture in traumatic brain injury are useful for the prediction of severity of orbital injury and its clinical outcome. This helps to identify patients in high risk and start early treatment to prevent permanent visual loss.
\end{abstract}

Key words: orbital fracture, traumatic brain injury, visual manifestation

$\mathrm{O}$ rbital manifestation in traumatic brain injury though uncommon, is one of the major complications that has to be addressed judiciously to prevent permanent visual loss. Almost half of the ocular trauma with or without head injury results into blindness. Partial loss of vision as a consequence of head injury has been overlooked in rural areas of developing countries. ${ }^{1}$ They commonly present very late carrying long-standing complete visual impairment. Our aim is to evaluate various ocular manifestations and correlate them with neuroophthalmic findings and analyze the significance between them.

18

Date submitted: 13/ 11/2019

\section{Material and Methods}

211 patients who underwent $\mathrm{CT}$ for traumatic brain injury in between September to December 2019 were prospectively analyzed for the orbital manifestation. All patients were recommended for CT head including orbit with $3 \mathrm{D}$ face RECON image for our study to remove the bias between fracture line and suture in plain CT scan. CT imaging was evaluated to identify and subtype the orbital fracture (Figure 1). Severity of head injury was scored according to Glasgow coma scale.

egneuro Volume 02, Issue 01, 2020 DOI:https://doi.org10.3126/egn.v2i1.27456

Date accepted: 10/12/2019 
Demographic details were obtained from the patient's clinical profile. Neuro-ophthalmic examination was done at bed-side and in outpatient department. Ophthalmology consultation was done in those cases with presence of significant orbital manifestations and was managed accordingly as per medical and surgical ethics. Bed-side examination included direct pupillary reaction, RAPD (relative afferent pupillary defect)/ Marcus Gun, bedside visual acuity test by counting fingers at 2 meter distance, extra-ocular movements and funduscopic examination. All data were entered into SPSS 20 for statistical analysis. Significant $P$ value was calculated using fisher exact test.

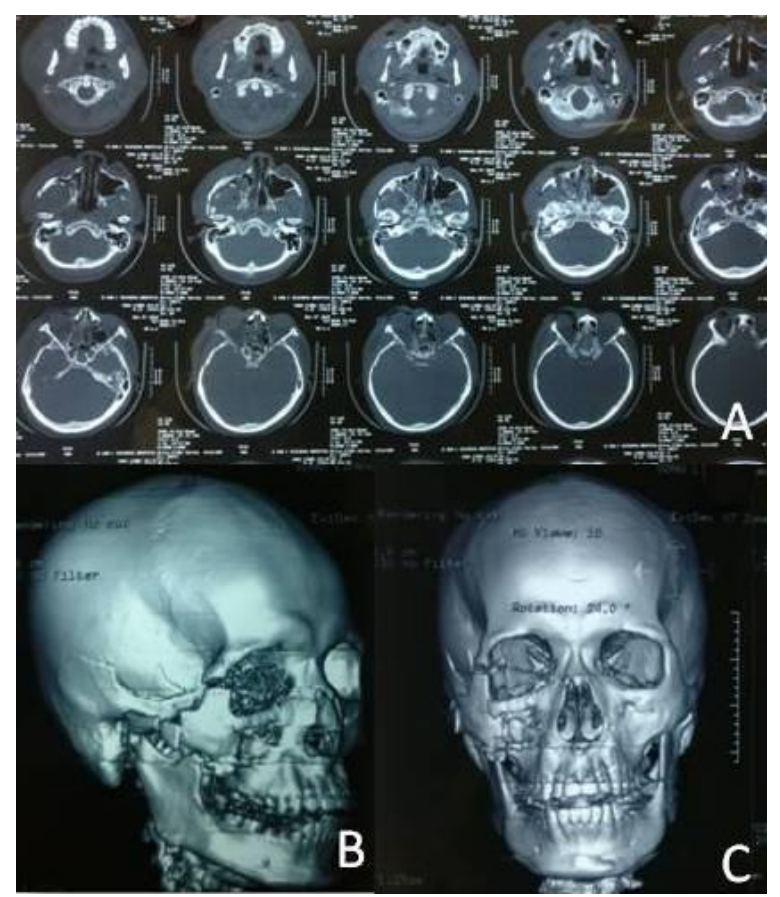

Figure 1 (A, B, C): CT head and orbit with 3D face RECON image

\section{Results:}

Total number of patients was 28 , with mean age of 33.82 (SD 17.15) years. Majority of the patients were male which accounted $79 \%$ of sample size (Figure 2). There was $78 \%$ mild head injury followed by $18 \%$ and $4 \%$ moderate and severe head injury respectively (Figure 3). Orbital fracture was classified based upon the different wall involvement. The most common type involved among the orbital fracture were blow out fracture and lateral orbital wall fracture (Figure 4). egneuro Volume 02, Issue 01, 2020
Clinically vision was abnormally around $21 \%$ of the cases, abnormal papillary reaction was seen in $25 \%$ of the cases around $93 \%$ of the cases had raccoon eye at the time of presentation (Table 1). There was proptosis in around 14\% of the patients and sub-conjunctival hemorrhage was seen in around $93 \%$ of the cases (Table 1).

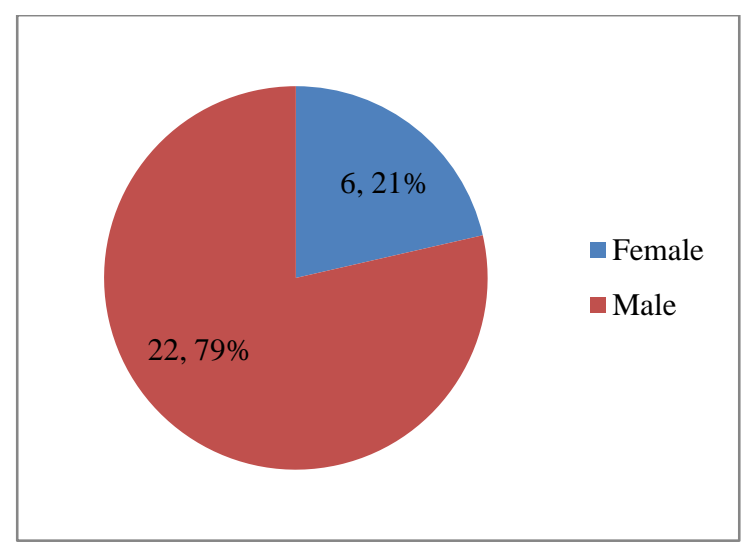

Figure 2: Distribution of gender

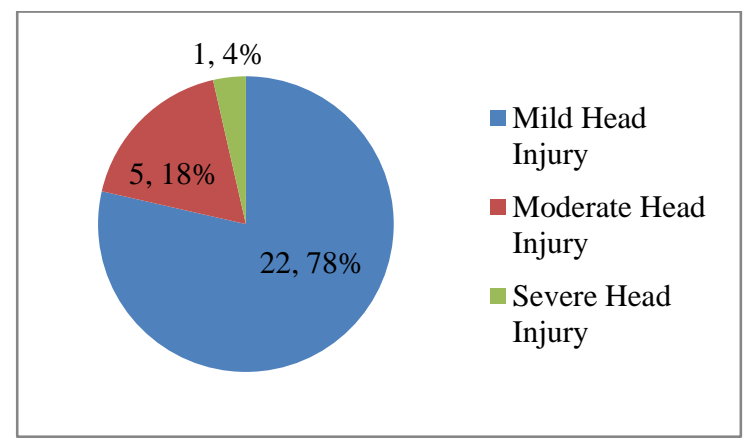

Figure 3: Severity of head injury

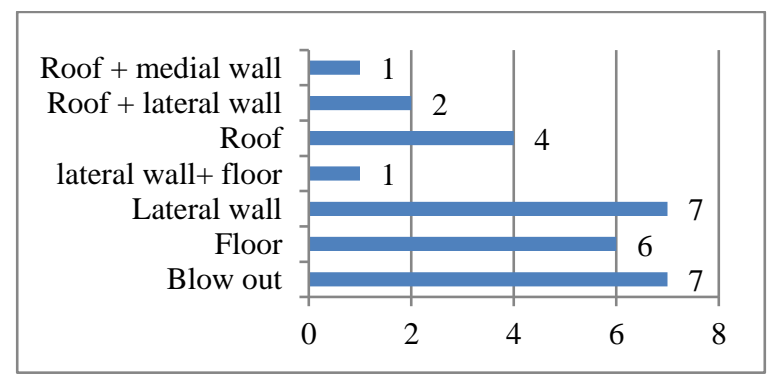

Figure 4: Various types of orbit fractures

Around $79 \%$ of the patients had intact vision at the time of presentation and $3.6 \%$ of the patients improve their vision during the course of treatment (Table 2). Complete globe injury who required evisceration of the eyeball was $10.7 \%$ and those 
who had abnormal vision at the time of presentation, $7.1 \%$ did not improve their vision.

Table 1: Frequencies of clinical signs

\begin{tabular}{llll}
\hline Categories & & Frequency & Percent \\
\hline \multirow{2}{*}{ Vision } & Absent & 5 & 17.9 \\
& Diminished & 1 & 3.6 \\
& $\mathrm{~N}$ & 22 & 78.6 \\
\hline \multirow{2}{*}{ Pupil } & Dilated & 3 & 10.7 \\
& MGunn & 4 & 14.3 \\
\multirow{2}{*}{ Raccoon eye } & $\mathrm{N}$ & 21 & 75.0 \\
\hline Sub & + & 2 & 7.1 \\
Conjunctival & - & 26 & 92.9 \\
Hemorrhage & + & 2 & 7.1 \\
\multirow{2}{*}{ Globe } & $\mathrm{N}$ & 26 & 92.9 \\
& Proptosis & 4 & 85.7 \\
\hline
\end{tabular}

(MGunn; Marcus Gunn, N; Normal)

Table 2: Vision outcome after orbital injury

\begin{tabular}{lll}
\hline & Frequency & Percent \\
\hline Normal & 22 & 78.6 \\
Evisceration & 3 & 10.7 \\
Improved to N & 1 & 3.6 \\
Not improved & 2 & 7.1 \\
\hline Total & 28 & 100.0 \\
\hline
\end{tabular}

(N; Normal)

Loss of the vision was not associated with gender; however severity of traumatic brain injury and the type of orbital fracture were significantly associated with initial visual loss (Table 3). Outcome of vision after treatment was significantly associated gender, severity of head injury and type of fracture with $P$ value $<0.05$ (Table 4).

\section{Discussion}

This study had done to identify ocular manifestation in traumatic brain injury with orbital trauma. Find ocular signs and symptoms early and treat accordingly are likely to have better clinical outcome. Treatment is usually delayed in those cases who present with low GCS with normal pupillary reaction. It is also very difficult to identify visual impairment in patient with low GCS with uncal herniation secondary to evolving intracranial hematoma and edema. Another neurosurgical condition, in higher grade of diffuse axonal injury, visual deterioration can be missed.
Hence concomitant severe head injury that needs to undergo hematoma evacuation, anterior cranial fossa repair, decompressive craniotomy, elevation of compound depressed fracture of basifrontal bone, visual manifestation is usually ignored. Subsequently patient walks home with loss of vision. To halt such poor condition, worsening features of ocular injury has to be identified early and do the needful. This is the main responsibility of treating neurosurgeon.

$5.3-19.7 \%$ of traumatic brain injury is associated with orbital injury. ${ }^{2}$ Although $78 \%$ of our patients sustained mild traumatic brain injury, however high velocity injury is common among young generation. Competitive bikers, poor traffic, drinking and riding habits and rough roads are the major shortcoming in developing countries like ours. Presence of facial injury, subconjunctival hemorrhage per orbital bruise or ecchymosis was significant to have orbital injury. ${ }^{3}$ This finding was consistent with our results. Similarly Barry et al had found the presence of ophthalmic manifestation in $60 \%$ of all type of orbital fracture. ${ }^{4}$ However this finding is not correlated with our result. There was a high correlation between subconjunctival hemorrhages, facial bone fracture with orbital bone fracture. ${ }^{5}$ Orbital fractures were sub-typed according to different wall involvement. The most common type involved among all were blow out fracture and lateral orbital wall fracture. According to various researches lateral wall fracture and blow out fracture is the common among all types. ${ }^{6,7}$ Lateral orbital wall is the toughest wall and its involvement is common due to force of impact being on lateral part of the orbit. Moreover Lateral wall is commonly involved during self rescue and protecting the eyeball during trauma. Facial injury is usually associated with such type of fracture. Patients frequently present with facial swelling and painful jaw movement. Articulation between greater wing of sphenoid and zygomatic bones is usually gets injured in lateral orbital wall fracture. Disruption of zygomatic articular site with involvement of basifrontal, temporal and maxillary bones is accompanied with lateral orbital wall fracture. ${ }^{8}$ Another common type of fracture is blow out fracture following direct impact on the eyeball from the front. ${ }^{7}$

egneuro, Volume 02, Issue 01, 2020 
Tamrakar (Karki) K et al.

Table 3: Association between different category and the loss of vision

\begin{tabular}{|c|c|c|c|c|c|}
\hline Category & Sub category & $\begin{array}{l}\text { vision } \\
\text { Absent } \\
\end{array}$ & Diminished & $\mathrm{N}$ & $\mathrm{P}$ value \\
\hline \multirow{3}{*}{ Gender } & Female & 2 & 1 & 3 & \multirow{3}{*}{0.09} \\
\hline & Male & 3 & 0 & 19 & \\
\hline & Mild Head Injury & 2 & 0 & 20 & \\
\hline \multirow[t]{5}{*}{ Sev head Injury } & Moderate Head Injury & 3 & 0 & 2 & \multirow[t]{5}{*}{$0.002 *$} \\
\hline & Severe Head Injury & 0 & 1 & 0 & \\
\hline & Blow out & 5 & 0 & 2 & \\
\hline & Floor & 0 & 0 & 6 & \\
\hline & Lateral wall & 0 & 0 & 7 & \\
\hline \multirow[t]{4}{*}{ Type of Fracture } & lateral wall+ floor & 0 & 0 & 1 & \multirow[t]{4}{*}{$0.002 *$} \\
\hline & Roof & 0 & 0 & 4 & \\
\hline & Roof + lateral wall & 0 & 1 & 1 & \\
\hline & Roof + medial wall & 0 & 0 & 1 & \\
\hline
\end{tabular}

$* \mathrm{P}$ value $<0.05$ (Sev head injury; Severity of head injury)

Table 4: Association of different category with outcome of vision

\begin{tabular}{|c|c|c|c|c|c|c|}
\hline Category & Sub category & vision outcome & Evisceration & Improved to $\mathrm{N}$ & Not improved & $P$ value \\
\hline \multirow{3}{*}{ Gender } & Female & 3 & 2 & 1 & 0 & \multirow{2}{*}{$0.042 *$} \\
\hline & Male & 19 & 1 & 0 & 2 & \\
\hline & $\begin{array}{l}\text { Mild Head } \\
\text { Injury }\end{array}$ & 20 & 1 & 0 & 1 & \multirow{3}{*}{$0.007 *$} \\
\hline \multirow[t]{5}{*}{ Sev head Injury } & $\begin{array}{l}\text { Moderate } \\
\text { Head Injury }\end{array}$ & 2 & 2 & 0 & 1 & \\
\hline & $\begin{array}{l}\text { Severe Head } \\
\text { Injury }\end{array}$ & 0 & 0 & 1 & 0 & \\
\hline & Blow out & 2 & 3 & 0 & 2 & \multirow{7}{*}{$0.026^{*}$} \\
\hline & Floor & 6 & 0 & 0 & 0 & \\
\hline & Lateral wall & 7 & 0 & 0 & 0 & \\
\hline \multirow{4}{*}{ Type of Fracture } & $\begin{array}{l}\text { lateral wall+ } \\
\text { floor }\end{array}$ & 1 & 0 & 0 & 0 & \\
\hline & Roof & 4 & 0 & 0 & 0 & \\
\hline & $\begin{array}{l}\text { Roof + lateral } \\
\text { wall }\end{array}$ & 1 & 0 & 1 & 0 & \\
\hline & $\begin{array}{l}\text { Roof } \\
\text { medial wall }\end{array}+$ & 1 & 0 & 0 & 0 & \\
\hline
\end{tabular}

*P Value $<0.05$ (Sev head injury; Severity of head injury)

93\% of the patients encountered with per-orbital ecchymosis (raccoon's eye) and subconjunctival hemorrhage as a common ophthalmic manifestation in our study at the time of presentation. Most of the patients (79\%) had normal vision during admission. Vision was abnormal in $21 \%$ of the cases. Among them, complete globe disruption who required evisceration of the eyeball was $10.7 \%$ and those who had abnormal vision at the time of presentation, $7.1 \%$ that did not improve their vision. There was proptosis in around $14 \%$ of the patients. 3.6\% of the patients improved their vision during the course of treatment. One presented late with post-traumatic optic neuropathy in association with moderate traumatic brain injury. Two patients with low GCS underwent bilateral decompressive intracranial surgeries for bi-frontal and temporal contusion. Though bilateral pupillary reaction was normal with no compressive radiological and clinical features, vision was found diminished after regaining GCS to normal level in one case. $75 \%$ of the cases had normal papillary reaction. RAPD was noted in four cases among $25 \%$ of abnormal pupillary presentation. Combination of two or more ocular findings was notable in all cases of orbital fracture in traumatic brain injury.

Traumatic orbital emergencies are another important issue that has to be addressed in suspected cases of orbital trauma with visual 
impairment. Accurate documentation of visual and orbital function is essential along with early ophthalmic consultation. Though optic nerve may not be compromised with fractured segment of bony orbital compartment, surrounding soft tissue injury can produce retro-bulbar hemorrhage. This subsequently results into rapid rise in intra orbital pressure reducing retinal and optic nerve blood flow and result into permanent vision loss. ${ }^{9}$ Rapid decrease of vision, acute pain, orbital congestion, tenderness, and proptosis are the major clinical identification of orbital compartment syndrome. Optic nerve damage occurs in 2-3\% of the traumatic brain injury primarily due to road traffic accidents. ${ }^{10}$ Direct injury occurs due to direct compression or laceration injury to optic nerve by bony fragments. Indirect injury occurs due to counter coup injury. Shearing of axons and pial vessels, disruption of axonal transport, result into optic nerve swelling and rise in optic canal pressure which further impair retinal blood flow ensuing ischemia. ${ }^{9}$ Indirect types of injury usually occur within the optic canal at the transitional zone between mobile and immobile vicinity like at orbital apex, close to the falciform dural fold. ${ }^{11}$ Reduced vision with or without altered color vision, presence of RAPD, fixed dilated pupils, concomitant traumatic brain injury are the main clinical keys for the diagnosis of traumatic optic nerve neuropathy. Lucid interval has also been described for traumatic optic neuropathy. Patient may have sudden vision drop caused by expanding optic nerve edema or hemorrhage in later hours or days. ${ }^{12}$ Orbital emphysema may sometime produce visual deterioration after trauma for which emergency needle decompression resulted in prompt improvement. ${ }^{13}$

\section{Conclusions}

Orbital manifestations with either type of orbital fracture in traumatic brain injury are useful for the prediction of severity of orbital injury and its clinical outcome. This helps to identify patients in high risk and start early treatment to prevent permanent visual loss.

\section{References}

1. Steinsapir KD, Goldberg RA. Traumatic optic neuropathy. Surv Ophthalmol. 1994;38:487-517.
2. Huang LK, Wang HH, Tu HF, Fu CY (2017) Simultaneous head and facial computed tomography scans for assessing facial fractures in patients with traumatic brain injury. Injury 48(7):1417-1422.

3. Holmgren EP, Dierks EJ, Assael LA, Bell RB, Potter BE (2005) Facial soft tissue injuries as an aid to ordering a combination head and facial computed tomography in trauma patients. J Oral Maxillofac Surg 63(5):651-654.

4. Barry C, Coyle M, Idrees Z, Dwyer MH, Kearns G (2008) Ocular findings in patients with orbitozygomatic complex fractures: a retrospective study. J Oral Maxillofac Surg 66(5):888-892.

5. Timashpolsky A, Dagum AB, Sayeed SM, Romeiser JL, Rosenfeld EA, Conkling N (2016) A prospective analysis of physical examination findings in the diagnosis of facial fractures: determining predictive value. Plast Surg (Oakv) 24(2):73-79.

6. Becelli, R., Renzi, G., Perugini, M., Iannetti, G. Craniofacial traumas: immediate and delayed treatment. J. Craniofac. Surg. 2000;11:265-9.

7. Kumari R, Saha BC, Saha KK, Sinha BP. Ocular manifestation in head injury patients-a prospective study. Int J Cont Med Res. 2017;4(8):1648-51.

8. Bell, R.B., Kindsfater, C.S., The use of biodegradable plates and screws to stabilize facial fractures. J. Oral. Maxillofac. Surg. 2006;64:31-9.

9. Lima V, Burt B, Leibovitch I, Prabhakaran V, Goldberg RA, Selva D. Orbital compartment syndrome: the ophthalmic surgical emergency. Survey of ophthalmology. $2009 \mathrm{Jul}$ 1;54(4):441-9.

10. Yu-Wai-Man P. Traumatic optic neuropathy-clinical features and management issues. Taiwan journal of ophthalmology. 2015 Mar 1;5(1):3-8.

11. Emanuelli E, Bignami M, Digilio E, Fusetti S, Volo T, Castelnuovo P. Post-traumatic optic neuropathy: our surgical and medical protocol. European Archives of Oto-Rhino-Laryngology. 2015 Nov 1;272(11):3301-9.

12. Mauriello JA, DeLuca J, Krieger A, Schulder M, Frohman L. Management of traumatic optic neuropathy-a study of 23 patients. British journal of ophthalmology. 1992 Jun 1;76(6):349-52.

13. Singh M, Phua VM, Sundar G. Sight-threatening orbital emphysema treated with needle decompression. Clinical \& experimental ophthalmology. 2007 May;35(4):386-7. 